\title{
ESCRITORES DEL SIGLO XIX FRENTE AL CUENTO FOLCLÓRICO*
}

\author{
Montserrat Amores García** \\ Universidad Autónoma de Barcelona
}

\begin{abstract}
RESUMEN. Durante el siglo XIX el cuento folclórico tuvo intenso cultivo. Muchos escritores se inspiraron en cuentos folclóricos para crear sus particulares cuentos literarios. Este artículo comenta brevemente la labor de los principales escritores decimonónicos que recolectaron cuentos folclóricos de boca del pueblo y distingue las principales actitudes adoptadas por aquéllos que cultivaron y reelaboraron cuentos folclóricos, señalando cómo el diferente concepto en que tuviesen este género etnopóetico explica en cierta medida los distintos grados de reelaboración ejercidos.
\end{abstract}

ABSTRACT. In nineteenth-century, short story was developed intensively as a genre. Frecuently Spanish writers took folktales as a starting point to create their stories. This paper explains briefly the works of first literary authors that collected folktales in Spain and distinguishs the first attitudes adopted by the authors who cultivated and recreated folktales, showing how the different judgements abaut folktales explain the different degrees of recreation.

De entre las formas narrativas tradicionales que recuperó el romanticismo, el cuento folclórico fue aquella que escritores como Fernán Caballero, Antonio de Trueba, Romualdo Nogués y Milagro, Luis Coloma, Juan Valera o Narciso Campillo cultivaron con más entusiasmo a partir de la segunda mitad del siglo XIX.

La lista de autores podría ampliarse a otros muchos que a lo largo de este periodo se inspiraron en alguna ocasión en relatos recogidos de la tradición. Juan de Ariza publicó en 1848 su cuento «Perico sin miedo», en el Semanario Pintoresco Español, reelaboración literaria del conocido cuento folclórico correspondiente al tipo 326A*,

* Recibido el 14 de marzo de 1994.

** Doctora en Filología Española, Profesora del Departamento de Filología Espanyola de la Universitat Autonoma de Barcelona, Edifici B, Bellaterra (Barcelona). 
según la clasificación internacional ${ }^{1}$. Al año siguiente, y en la misma revista, apareció la particular versión de José Godoy Alcántara del cuento de las tres preguntas, titulado «Un abad como hubo muchos, y un cocinero como no hay ninguno» (tipo 922)2. En 1852 Pedro Antonio de Alarcón escribió su primera versión de «El amigo de la muerte», inspirado en el cuento convencionalmente conocido como "La muerte madrina" (tipo 332), y que apareció en El Eco de Occidente. En 1862 Manuel Ossorio y Bernard reelaboró el cuento del pescador y su mujer (tipo 555), que tituló «Un cuento de viejas», y publicó en El Museo Universal ${ }^{3}$. En 1882 José $\mathrm{M}^{\mathrm{a}}$ de Pereda incluyó en su novela El sabor de la tierruca un precioso cuento folclórico tìtulado «El zonchero cudicioso» (tipo 555). Emilia Pardo Bazán escribió una deliciosa versión del cuento del zapatero pobre (tipo 754) titulada «Los zapatos viejos», que apareció en la revista Blanco y Negro, en $1899^{4}$. Estos pocos ejemplos pueden confirmar el fructífero cultivo del cuento folclórico en el siglo XIX y la gran variedad de autores que acudieron a este género etnopoético para crear sus propios cuentos literarios.

El tratamiento culto que esta forma.narrativa tradicional experimentó en manos de los autores decimonónicos fue muy variado. Desde aquellos que intentaron transmitir el relato folclórico tal y como lo recogieron del pueblo, hasta aquellos otros que simplemente se inspiraron en ellos, y transformaron completamente el relato originario.

Una de las principales causas que explican su mayor o menor grado de reelaboración se encuentra en el diferente concepto que cada autor tenía de las creaciones populares y su actitud ante el cuento folclórico tal y como era transmitido por el pueblo. Las razones ideológicas y estéticas que estimularon a cada escritor a cultivar el cuento folclórico motivaron una distinta aproximación a este género de literatura oral y, por lo tanto, una actitud recreadora diferente.

\section{Los recolectores de cuentos folclóricos.}

El análisis del tratamiento culto del cuento folclórico en el siglo XIX debe partir, en primer lugar, de la distinción entre los autores que dedicaron parte de su quehacer a recolectar y publicar cuentos folclóricos de tradición oral, y aquellos que sólo en ocasiones se inspiraron en un relato folclórico para escribir sus cuentos, ya sea acudiendo a su memoria, refiriendo un cuento folclórico recientemente escuchado o bebiendo de fuentes escritas.

Entre los recolectores debe considerarse indiscutiblemente a Fernán Caballero, Antonio de Trueba, Juan Valera y Romualdo Nogués y Milagro. Los cuatro mostraron

1. A. Aarne y S. Thompson, The types of the folktale: a classification and bibliography, Helsinki: Suomalainen Tiedekatemia-Academia Scientiarium Fennica (FF Commnunications, 184), 19733.

2. Semanario Pintoresco Español (1849) pp. 236-238.

3. El Museo Universal, $\mathrm{n}^{\circ} 4$ (26 de enero de 1862) pp. 28-29.

4. Blanco y Negro, $\mathrm{n}^{\circ} 410$ (11 de marzo de 1899). 
deleite por la literatura popular, preocupación por recuperar sus creaciones, y se entregaron en mayor o menor medida a la tarea de recolección de este género etnopoético. Recibieron la influencia directa o indirectamente de las ideas de Herder, los hermanos Grimm y teóricos posteriores, y admitieron la recolección y publicación de cuentos folclóricos como una labor.

Cecilia Böhl de Faber fue la pionera en la recolección de cuentos folclóricos del pueblo andaluz. Las primeras noticias de relatos tradicionales recogidos por la hija de Juan Nicolás Böhl de Faber y Francisca Larrea se remontan a los primeros años de su matrimonio con el marqués de Arco-Hermoso, entre 1822 y $1825^{5}$. En sus novelas se diseminan muchos cuentos folclóricos, y fue por lo menos a partir de $1856^{6}$ cuando empezó a preparar los volúmenes de Cuentos y poesías populares andaluces de 1859, y los Cuentos, oraciones, adivinas y refranes populares e infantiles de 18777.

Fue con toda probabilidad la publicación del primer volumen de cuentos de Fernán Caballero el incentivo que necesitaba Antonio de Trueba para que él también se decidiera a cultivar el cuento folclórico. Antes se había dedicado a la poesía popular con gran éxito y a los cuentos literarios cargados de un acentuado sentimentalismo ${ }^{9}$. Tras la aparición de los Cuentos y poesías populares andaluces de Fernán, Trueba inició la publicación de colecciones de cuentos en los que se incluyen numerosos de carácter folclórico. Así, en los Cuentos campesinos de 1860 aparece algún que otro chascarrillo en sus narraciones, y con la publicación de los Cuentos populares, en 1862, inició el autor vasco conscientemente su tarea recolectora. Le siguieron los Cuentos de varios colores, de 1866. El cultivo de este género etnopoético parece llegar a su punto álgido con la publicación, en ese mismo año, de los Cuentos de vivos y muertos, que posee en sus mayoría reelaboraciones de cuentos folclóricos. Por aque-

5. Véase la primera carta que incluye el padre Diego de Valencina en Fernán Caballero. Cartas, Madrid: Sucesores de Hernando, 1919, p. 2. Javier Herrero demostró en su momento, y sus conclusiones fueron corroboradas por Julio Rodríguez-Luis, que esta carta no fue escrita, como suponía Valencina, en 1834, sino en fecha tempranísima y durante los primeros años del matrimonio de Cecilia Böhl de Faber con el marqués de Arco-Hermoso. [Véase. J. Herrero, Fernán Caballero: un nuevo planteamiento, Madrid: Gredos, 1963, pp. 284-285; y J. Rodríguez-Luis, "Introducción" a Fernán Caballero, La familia de Alvareda, ed. J. Rodríguez-Luis. Madrid: Castalia, 1970, pp. 23-24].

6. De 1856 son las primeras noticias epistolares de la autora acerca de la preparación de un volumen dedicado a géneros etnopoéticos. En una carta dirigida a Juan Eugenio Hartzenbusch, la autora comunica a su amigo que Fermín de la Puente y Apezechea la ha instado a organizar todo el material de origen popular que posee y compendiarlo en "un tomo de poesías, cuentos etc. populares andaluces" [Véase T. Heinemann, Cecilia Böhl de Faber y Juan Eugenio Hartzenbusch, Madrid: Espasa-Calpe, 1944, p. 182].

7. Fernán Caballero, Cuentos y poesías populares andaluces, Sevilla: Imprenta de la Revista Mercantil, 1859; Cuentos, oraciones, adivinas y refranes populares e infantiles, Madrid: Imprenta de T. Fontanet, 1977.

8. Antonio de Trueba se da a conocer con la poesía popular publicando en 1851 El libro de los cantares, que en 1875 andaba ya por su octava edición, sin contar con las fraudulentas de Leipzig.

9. En 1859 publicó Colorín, colorado... Cuentos y los Cuentos de color de rosa. Ninguno de los dos volúmenes contiene cuentos folclóricos recogidos de la tradición oral. 
llos años Antonio de Trueba se dedicaba a su labor como cronista y archivero del Señorío de Vizcaya, trabajo que debió facilitar sus viajes y paseos por tierras vascas recogiendo material. A partir de entonces el cultivo del cuento folclórico fue continuo en el autor. Se diseminan en sus Narraciones populares, de 1874, en los Cuentos del hogar, de 1875, en Nuevos cuentos populares, de 1880 y en la publicación póstuma del volumen Cuentos populares de Vizcaya en $1905^{10}$.

Fernán Caballero y Antonio de Trueba son los dos autores que demuestran más abiertamente la deuda debida al romanticismo alemán. A pesar de los resultados tan diversos en lo que se refiere a la reelaboración de sus cuentos folclóricos, de lo que no cabe duda es de que fueron los primeros, aunque no los únicos, en preocuparse por recoger y publicar los cuentos folclóricos españoles, movidos por la necesidad de rescatarlos de su inevitable pérdida, según sus pareceres.

Por otra parte, Juan Valera y Antonio $M^{a}$ Segovia iniciaron en 1860 la publicación de relatos de carácter tradicional con Florilegio de cuentos, leyendas y tradiciones vulgares. Desgraciadamente sólo apareció la primera entrega, que contenía una interesante "Introducción" a la obra escrita por Juan Valera11, y su precioso cuento «El pájaro verde». En 1894, Juan Valera escribió y reelaboró «La muñequita» y «La buena fama», e incluso tradujo cuentos japoneses como «El espejo de Matsuyama» $\mathrm{y}$ «El pescadorcito de Urashima». En 1896 publicó, junto con Narciso Campillo, Mariano Pardo de Figueroa y el conde de las Navas, los Cuentos y chascarrillos andaluces ${ }^{12}$. Que Valera y estos autores se preocuparon de recoger y coleccionar cuentos folclóricos, especialmente chascarrillos, lo corroboran las palabras que dirigió el primero al doctor Thebussem cuando el librito estaba preparado para la imprenta:

No crea usted por eso que "Las orejas" y los demás cuentos excluidos, que pasan de veinticinco, ya redactados, y de más de doscientos por redactar, han caído en saco roto. Muy al contrario, archivados quedan y conservados como oro en paño ${ }^{13}$.

10. Cuentos campesinos, Madrid: Imprenta de "La Correspondencia de España", 1860. Cuentos populares, Madrid: Imprenta de D.L. Palacios, 1862. La primera edición, que contenía los cinco primeros cuentos llevaba por título Colorín, colorado... Cuentos, Madrid: Imprenta de El Atalaya, 1959. Cuentos de varios colores, Madrid: Imprenta del Centro General de Administración, 1866. Cuentos de vivos y muertos, Madrid: Librería de don Leocadio López editor, 1866. Narraciones populares, Madrid: A. Jubera, editor, 1874. Cuentos del hogar, Madrid: Imprenta y Librería de Miguel Guijarro, 1875. Nuevos cuentos populares, Madrid: Ilustración Española y Americana, 1880. Cuentos populares de Vizcaya, Madrid: Antonino Romero, 1905.

11. Recogida por C. DeCoster en Obras desconocidas de Juan Valera, Madrid: Castalia, 1965, pp. 81-88.

12. Cuentos y chascarrillos andaluces, Madrid: Fernando Fe, 1896.

13. Santiago Montoto, "Curiosidades literarias: las amarguras de don Juan Valera", El Sol, 13 de octubre de 1926, p. 4. 
Romualdo Nogués y Milagro debe considerarse el siguiente autor, por orden cronológico, cuyo principal interés, antes que el puramente literario, fue la recolección de cuentos folclóricos. Este "soldado viejo natural de Borja" -así firmaba el escritor sus libros- recogió y publicó sistemáticamente cuentos folclóricos del pueblo aragonés en sucesivas colecciones, movido por las mismas inquietudes que Fernán Caballero, Antonio de Trueba y Juan Valera. Su obra es posterior: en 1881 publicó la primera serie de Cuentos, dichos, anécdotas y modismos aragoneses, a la que siguió la segunda, en 1885; en 1886 publicó los Cuentos para gente menuda, y en 1898 los Cuentos, tipos y modismos de Aragón ${ }^{14}$. Su trabajo en el foclor aragonés, y sobre todo en la recolección de cuentos, es comparable al que Fernán hizo en Andalucía. A excepción del volumen de Cuentos para gente menuda, dirigido al público infantil, la reelaboración del resto de las colecciones es mínima. Dice en el prólogo a su colección de 1881:

A falta de proezas, refiero cuentos aragoneses. Con elíos entretenía a mis compañeros durante las deliciosas veladas que pasamos casi a la intemperie en el campamento de Monte Esquinza (...). Entonces se me ocurrió coleccionarlos, evitando repetir lo ya publicado, sin inventar nada, tratando de darles forma adecuada para toda clase de lectores, deshechando con sentimiento muchos por su color subido, que son los que tienen más sabor local, y suprimiendo por imposible la salsa de las interjecciones ${ }^{15}$.

Por otra parte, a pesar de que la publicación de sus volúmenes coincidió con los primeros trabajos de «Demófilo» y el Folk-lore Andaluz, (1882-1883), no parece que Nogués y Milagro trabajara en este campo interesado por la etnología:

Sin meter bulla, llamar la atención, ni valerse de palabras extranjeras difíciles de pronunciar, y que los del vulgo no entendemos, es muy fácil recoger, coleccionar y publicar los cuentos, anécdotas y cantares que inventa el pueblo y conserva la tradición. No se pierden, sirven de solaz, y se consigue formar una literatura propia del genio particular de cada comarca ${ }^{16}$.

La alusión a la palabra "folklore" y a la escuela positivista de «Demófilo» es clara. Basten estas palabras para destacar el importante papel que jugó este escritor como recolector de cuentos folclóricos.

14. Cuentos, dichos, anécdotas y modismos aragoneses, que da a la estampa un soldado viejo natural de Borja, Madrid: Imprenta de Pérez Dubrull, 1881. Cuentos, dichos, anécdotas y modismos aragoneses, que da a la estampa un soldado viejo natural de Borja, segunda serie, Madrid: Imprenta de Pérez Dubrull, 1885. Cuentos para gente menuda, que da a la estampa un soldado viejo natural de Borja, Madrid: Imprenta de A. Pérez Dubrull, 1886. Cuentos, tipos y modismos de Aragón, Madrid: Fernando Fe, 1898.

15. De los Cuentos, dichos, anécdotas y modismos aragoneses, de 1881, p. VII.

16. Cuentos, dichos, anécdotas y modismos aragoneses, segunda serie, p. V. 
No existe constancia alguna de que Luis Coloma, a pesar de que recreó un número no despreciable de cuentos folclóricos, aceptase la recolección de cuentos como un proyecto. Como afirma Ana Luisa Baquero Escudero "si del esfuerzo de Fernán por recoger directamente de la boca del pueblo no hay que dudar ... no ocurre lo mismo con Coloma. A excepción de «Historia de un cuento», transcrito, según el autor, tal y como le fue referido, en ninguna otra ocasión alude Coloma a su papel de recolector más o menos sistemático de cuentos folclóricos"17.

\section{Diferentes actitudes, distintos tratamientos literarios}

No obstante, dentro de este grupo de recolectores, es necesario distinguir dos actitudes generales muy diferentes de las que derivan el grado de reelaboración que ejercieron sobre el material recolectado. Se aúnan entonces las concepciones de Fernán Caballero y Romualdo Nogués y Milagro frente a las presentadas por Antonio de Trueba y Juan Valera.

Atenta a lo que ocurría en Europa, Fernán Caballero señaló la necesidad de cultivar y recolectar cuentos folclóricos. Los hermanos Grimm fueron su modelo. De ellos tomó el concepto de fidelidad que aplicaría a la elaboración de sus cuentos folclóricos. Sin embargo, la aproximación al pueblo de Fernán Caballero obedecía primordialmente a preocupaciones ideológicas y estéticas. Fernán partía de los presupuestos del romanticismo alemán y del tradicionalismo, que aprendió de Herder y de sus padres, para buscar en el pueblo y en sus creaciones la identidad nacional y los valores perdidos. En 1855 escribía a Manuel Cañete:

\footnotetext{
"Usted habrá comprendido ya mi idea de entremeter siempre coplas y versos devotos y populares en mis composiciones. Mi fin es hacer conocer el numen político y religioso de nuestro pueblo"18.
}

El alto concepto que tenía del pueblo y las creaciones populares le llevaron a que intentase que los cuentos folclóricos recolectados transmitiesen fielmente el verdadero espíritu popular. El error radicaba en que ese genuino espíritu del pueblo español no era real sino ideológico ${ }^{19}$. Por ello la selección ideológica y literaria, y el trasfondo moralista y paternalista se deja sentir en los cuentos folclóricos que se diseminan en sus novelas y sus volúmenes de cuentos, ya mencionados. Partiendo de un peculiar concepto de fidelidad con lo recolectado, los cuentos populares, que incluyó en

17. Véase Ana Luisa Baquero Escudero, "El cuento popular en el Siglo XIX", Anales de la Universidad de Murcia, 48 (1984) p. 365.

18. A. López Argüello, Epistolario de Fernán Caballero, Madrid: C.S.I.C., 1922, p. 33.

19. Véase J. F. Montesinos, Fernán Caballero, ensayo de justificación, México: El colegio de México, 1961, especialmente capítulos IV y V. 
Cuentos y poesías populares andaluces de 1859 debían reflejar el carácter del pueblo andaluz: su religiosidad, su agudeza, su amor a la patria... proyectando siempre la imagen subjetiva que de éste tenía la autora. Con los Cuentos, oraciones, adivinas y refranes populares e infantiles de 1877 Fernán se hace eco de la consolidación de la literatura infantil en el siglo XIX. Aquellas creaciones populares, cuyo público son generalmente los niños, fueron publicadas por Fernán con el propósito de mostrar el candor, la sencillez y el ingenuo sentimiento religioso, rasgos propios de la infancia según su opinión, además de aleccionar a los pequeños de manera más o menos sutil.

Sólo desde esta actitud frente a las creaciones populares y de su aplicación a los diferentes subgéneros etnopoéticos, se entiende que Fernán Caballero fuese bastante respetuosa con el espíritu de los cuentos folclóricos que cultivó, a pesar de que en ocasiones alterase la trama del cuento folclórico, o infundiese a la narración elementos moralizadores. Creyendo que las creaciones populares expresaban en sí mismas el genuino espíritu nacional que debía difundirse, sólo era necesario transmitirlas lo más fielmente posible, a pesar de que su sistema contenía como puede columbrarse una engañosa trampa derivada de los presupuestos ideológicos de los que partía.

Fernán Caballero y Romualdo Nogués mantuvieron de forma general los cuentos folclóricos tal y como los recogieron, puesto que creyeron que era justamente respetando en lo posible su forma originaria, cuando expresaban más auténticamente el carácter del pueblo que los transmitía. A Nogués le estimulaba, además, el impulso regionalista, comparable en ciertos aspectos al fuerismo de Trueba. Fernán Caballero recogió los cuentos de Andalucía pero identificándolos con los de España. Trueba y Nogués y Milagro identificaron los cuentos folclóricos que recogieron en el País Vasco y Aragón respectivamente con la expresión sincera del verdadero carácter vasco y aragonés.

El caso de Luis Coloma es un tanto paradójico. La dependencia con respecto a Fernán Caballero es evidente. Retomando casi al pie de la letra las palabras de su maestra escribía al inicio de "La resignación perfecta" de 1884:

Lo que vamos a referir no es invención nuestra: es una de esas verdaderas fábulas ascéticas, que brotan del corazón de ese eminente poeta que se llama pueblo, cuando el sentimiento religioso le inspira; exacto regulador que marca al hombre de observación, los grados de arraigo y de pureza de las creencias religiosas de quien así sabe sentirlas y expresarlas. En todas las naciones cultas de Europa se estudian y se coleccionan hoy las tradiciones y cantos populares, como medio de conocer la índole de cada pueblo: este mismo estudio, apenas cultivado en España, ha probado, sin embargo, que era el nuestro un gran poeta religioso, a quien inspiraba su robusta fe bellísimas al par que profundas creaciones, que adornan sus creencias sin deslustrar en nada su pureza dogmática ${ }^{20}$.

20. Luis Coloma, Cuadros de costumbres populares, en Obras Completas, Madrid: "Razón y Fe", 1940, (vol. II), p. 17. 
El gusto por los cuentos folclóricos que escuchaba del pueblo y el concepto que de ellos tenía se debe a los preceptos que aprendió de la pionera en la recolección. También provienen de Fernán Caballero sus ideas con respecto al pueblo, aunque en Luis Coloma se radicalizan hacia posiciones extremadamente populistas. Parecida posición es la que se observa en la reelaboración de sus cuentos folclóricos. Imitando a su maestra introdujo en algunas novelas chascarrillos, sin alterar en absoluto su contenido, y recreando mejor que Fernán su enunciación. Sin embargo, extremó la intención moralizadora de los cuentos folclóricos que escribió dirigidos a los niños ${ }^{21}$, y que también aprendió de Fernán, aunque su maestra fuera mucho más moderada.

Frente al mínimo grado de reelaboración de Cecilia Böhl de Faber y Romualdo Nogués y Milagro, se encuentra la recreación o restauración de los cuentos que llevaron a cabo Antonio de Trueba y Juan Valera, con actitudes y resultados muy diferentes. Coincidían, no obstante, en un aspecto que les llevó justamente a considerar que los cuentos populares, como diría Trueba, y los cuentos vulgares, como los liamaba Juan Valera, necesitaban cierto acomodo para poder formar parte de la Literatura.

Para Antonio de Trueba los cuentos eran "guijarros que andan rodando por los campos" o "perlas de inestimable valor que se encuentran entre su cieno"22. La inverosimilitud, la carencia de enseñanza moral y la forma desaliñada eran los principales errores de los cuentos folclóricos tal y como eran transmitidos por el pueblo:

Recoger los cuentos populares y darlos a luz tales como el pueblo los cuenta ... tendrían en España un inconveniente literario y otro moral. El inconveniente literario sería la falta de interés, como consecuencia de la inverosimilitud y carencia de arte, que en casi todos los cuentos son tales, que éstos sólo sirven para embobar chiquillos ... El inconveniente moral sería aún más grave, porque la mayoría de los cuentos populares, o no enseñan nada, o enseñan lo que la moral y el buen sentido rechazan ${ }^{23}$.

Por ello se alejó voluntariamente de la labor recolectora de autores como los hermanos Grimm o Fernán Caballero para obrar más como escritor literario que como recopilador. Su labor recreadora intentaba subsanar aquellos defectos que encontró en este género de literatura oral y por esta razón actuó profundamente sobre el material folclórico transformándolo en ocasiones totalmente.

La opinión que de ellos, sobre todo de los cuentos folclóricos maravillosos, tenía Juan Valera se aproxima en algunos aspectos a la de Trueba. Avalado por autoridades como Max Müller o Jacob Grimm, para Valera los "cuentos vulgares" debían conside-

21. Cuentos para niños, en Obras Completas VI, Madrid: Editorial "Razón y Fe", 1941.

22. La primera cita aparece en el cuento titulado «La verdad», Cuentos populares de Vizcaya, p. 226; la segunda, en «Tres cuentos populares», Almanaque de la Ilustración, Madrid: Sucesores de Rivadeneyra, 1881, p. 91.

23. Nuevos cuentos populares, p. 6. 
rarse restos de antiguas mitologías y fragmentos de poesía épica que habían llegado a Europa desde el remoto Oriente, y el paso del tiempo ha desfigurado totalmente ${ }^{24}$. Como escritor, y coincidiendo con Antonio de Trueba y Narciso Campillo, su inclinación por el folclor no se circunscribía únicamente a la de recolector. En el prólogo a Una docena de cuentos de Narciso Campillo se refiere a su afición a los cuentos y su empeño "(...) en contribuir a que esta afición se extienda a coleccionarlos, revistiéndolos de forma literaria y duradera" 25 .

El primer proyecto fue el que emprendió junto a Antonio María Segovia al publicar en 1860 la primera entrega de lo que iba a ser el Florilegio de cuentos, leyendas y tradiciones vulgares. En su "Introducción" incide en uno de los aspectos por los que considera la necesidad de reelaboración de los cuentos folclóricos. Dice Valera:

Aunque damos importancia a los cuentos de viejas, no los tenemos por perfecta y verdadera poesía, sino por el germen de ella. La poesía se perfecciona y aún se constituye con la hermosura de la forma, y los cuentos no la tienen ${ }^{26}$.

De esta concepción del cuento folclórico deriva la actitud que emprende al restaurar la «La muñequita» en «La buena fama» (1894) o años antes «El pájaro verde» (1860) que recreó después de haberlo escuchado desde niño y oído probablemente de boca de la duquesa de Rivas ${ }^{27}$.

En este sentido su quehacer es comparable al de otros autores europeos según los juicios expresados en su artículo "Breve definición del cuento":

Por lo general, con todo, puede afirmarse que los cuentos más lindos, escritos por autores de fama, se fundan en tradición oral, han peregrinado mucho, han ido de boca en boca por todos los países, y el autor que los ha escrito sólo ha puesto en ellos el estilo, dándoles, si el estilo es gracioso y perfecto, su redacción y forma definitiva. De este género son: El asno, de Lucio Patrás; la historia de Psiquis y Cupido que infiere Apuleyo en su famosa novela; La matrona de Efeso, insertado por Petronio en el Satiricón; El jocondo y El perro precioso, que forman dos episodios del Orlando, de Ariosto y más modernamente, los cuentos de Perrault, de madame D'Aulnoy y de madame Prince de Beaumont, en Francia; de Musaus y el canónigo Schmidt en Alemania, y de Andersen, en Dinamarca 28 .

24. Véase su "Breve definición del cuento" que escribió hacia 1890 para el Diccionario Enciclopédico Hispanoamericano o la "Introducción" a los Cuentos y chascarrillos andaluces de 1896 en Obras completas, Madrid: Aguilar, 1961 (Vol. II), pp. 1.045-1.049 y 1.209-1.213.

25. J. Valera, Obras Completas, II, p. 525; la cursiva es mía.

26. En Cyrus C. DeCoster, Op. cit., p. 86.

27. Así lo expresa en la dedicatoria al duque de Rivas de Cuentos y diálogos, Sevilla, Alvarez, 1882. [Véase Cyrus C. DeCoster, Op. cit., p. 95].

28. Obras Completas, (vol. I), p. $1047 \mathrm{~b}$. 
Tanto Antonio de Trueba como Juan Valera creyeron necesaria la recreación de los cuentos folclóricos debido al concepto que de este género etnopoético tenían. No obstante, la literaturización fue totalmente distinta. Juan Valera intentaba devolver a los cuentos aquellos elementos que se habían borrado con el paso del tiempo y que los relacionaban con los relatos mitológicos o su origen asiático. Trueba, sin embargo, sólo pensaba en darles una forma más adecuada y, sobre todo, introducir la enseñanza moral. Valera supeditaba la moralidad a la literatura, mientras que para Trueba la dependencia era contraria. La diferente calidad de sus creaciones es evidente. Juan Valera divierte al lector a la vez que muestra sugerentes y sorprendentes reflexiones de carácter moral. Frente a la sutileza de los cuentos de Valera, la insistente y maniqueísta visión de los comportamientos humanos de Trueba.

\section{El cuento folclórico como modelo o como fuente}

El resto de escritores decimonónicos que únicamente se inspiraron en ocasiones en cuentos folclóricos para crear sus particulares narraciones, y de los que he mencionado unos pocos al iniciar este trabajo, encontraron en los cuentos folclóricos un precioso molde en el que introducir sus aspiraciones creativas.

Si para Fernán Caballero y Romualdo Nogués y Milagro el cuento foclórico fue modelo genérico a seguir, para el resto los relatos orales escuchados de boca del pueblo fueron fuente y como tal se inspiraron en ellos, utilizaron su trama argumental respetándola en mayor o menor medida, pero haciendo énfasis en otros aspectos ajenos a las licencias y teorías de este género de literatura oral. El cuento folclórico llamó su atención ya fuese por lo inusitado de su trama, por la originalidad de lo maravilloso, o por el gracejo y comicidad de su resolución. El principal y más general objetivo propuesto por ellos fue el de otorgar al argumento folclórico un "aire de realidad" del que carecía la escueta y desnuda trama; convertir lo inaudito de su ficción en verosímil ${ }^{29}$. El desarrollo de la acción, centro principal en torno al cual gira este género etnopoético, pasó a un segundo plano. El centro de interés se trasladó a otros aspectos. La creación de personajes, la composición de ambientes, la incorporación o potenciación de una reflexión de carácter moral... se integraron de una manera u otra en la composición del cuento literario.

El género etnopoético se acomodó con mayor o menor tensión a las tendencias literarias de la época. Desde el tratamiento romántico en la pluma de José Zorrilla, pasando por el tono costumbrista de algunos cuentos de Antonio de Trueba, hasta la intención realista que José $\mathrm{M}^{\mathrm{a}}$ de Pereda intentó transmitir en los suyos. En definitiva, el cuento folclórico fue cultivado por estos autores como simple material susceptible

29. Véase V. Propp, "Folklore and Reality", en Therory and History of Folklore, Oxford: Manchester University Press, 1984, p. 19. 
de convertirse en literatura y por lo tanto las características específicas del género etnopoético se subordinaron a las puramente literarias.

Fernán Caballero y Romualdo Nogués y Milagro se aproximaron, en la medida de sus posibilidades, a las incipientes teorías y trabajos del folclor. Recolectaron y publicaron cuentos folclóricos con mayor o menor fidelidad intentando dar a conocer las creaciones y el pensamiento del pueblo.

Una actitud intermedia fue la adoptada por escritores como Antonio de Trueba, Juan Valera o Narciso Campillo, entre otros. Con el propósito de recuperarlos, recolectaron cuentos folclóricos, pero los incorporaron a la literatura después de restaurarlos profundamente. Tal era el concepto en el que tenían este género etnopoético.

Para la mayoría de autores decimonónicos que recrearon cuentos folclóricos éstos fueron valiosos relatos tradicionales pertenecientes a la colectividad que prohijaron conviertiéndolos, después de un laborioso proceso de reelaboración, en personales cuentos literarios. 